\title{
EVALUATING THE INFLUENCE OF COUNTRY POLICY ON CARBON DIOXIDE EMISSIONS TRADINGS
}

\author{
Yoshihisa INOUE* and Hiroyuki TAMURA** \\ *Technology Information Department, National Institute of \\ Advanced Industrial Science and Technology (AIST) \\ **Faculty of Engineering, Kansai University
}

\begin{abstract}
In this paper, we consider carbon tax and emissions trading as the national policy against the global warming problem. The attitude of the United States, whether they join the international carbon dioxide emissions trading under the Kyoto Protocol or not, will bring a large influence on the global environment and the emissions trading. Therefore, we evaluate the influence on the revenue, the price of carbon dioxide emissions trading, and the amount of carbon dioxide emissions, etc, for the cases, such as U.S. join the Kyoto Protocol or not, using the mathematical model which consists of Japan, U.S., U.K., France, Germany and Russia, and which takes into account the cost of carbon dioxide reductions. Copyright (C) 2005 IFAC
\end{abstract}

Keywords: Modeling, environments, economics, mathematical model, optimization, linear programming.

\section{INTRODUCTION}

The global warming can be said as one of the most severe environmental problems that we have today. As the first steps of the international counter policy for this problem, the reduction target of the greenhouse gasses emissions was negotiated in the Kyoto Protocol at COP3. However, the United States dropped out, and Russia hesitates to ratify, therefore, the Kyoto Protocol has not come into effect yet.

In this paper, we consider the carbon tax and the emissions trading in order to meet the $\mathrm{CO}_{2}$ emissions reduction target, and evaluate the economic influence on the industry in each country.

\section{EVALUATION MODEL}

We adopt the mathematical model that was established in Akazawa, et al. (2002). The objective countries are Japan, United States, United Kingdom,
France, and Germany. The industry of these countries is classified into 10 sectors as shown in Table 1. Russia is added as an emissions permits supplier in the emissions trading. This model consists of a profit maximization problem and sub-problems. The former problem is based on input-output analysis and expresses the profit maximization behavior of each country, which introduce the carbon tax and the emissions trading to meet the emissions reduction target. The later problems express domestic transaction, inter- national trades, and the $\mathrm{CO}_{2}$ cost, which describes the cost to reduce $\mathrm{CO}_{2}$ and the cost for paying carbon tax.

The profit maximization problem is written as,

$$
\begin{gathered}
\max _{x, v} p(x, v) x-p(x, v)(A-M) x-k(x) \\
\text { subject to }(I-A+M) x=d(p)+w
\end{gathered}
$$

where, $p(*)$ denotes a domestic price vector, $x$ denotes an output vector, $v$ denotes a value-added vector, $\boldsymbol{A}$ denotes an input-output coefficient matrix, $\boldsymbol{M}$ denotes an import coefficient matrix, $k\left({ }^{*}\right)$ denotes a $\mathrm{CO}_{2}$ cost, $d\left(^{*}\right)$ denotes a domestic final demand 
vector, and $w$ denotes an export vector.

Table 1. Classification of industrial sectors

Sec. 1 Agriculture, Forestry and Fishery / Food product

Sec. 2 Fiber / pulp, wooden goods

Sec. 3 Chemistry product / Petroleum product

Sec. 4 Steel / Nonferrous metal / Metal

Sec. 5 General machinery / Electricity machinery

/ Precision machinery

Sec. 6 Other manufacturing industry

Sec. 7 Construction

Sec. 8 Transportation

Sec. 9 Service

Sec. 10 Others

Changes of the domestic final demand is written as,

$$
d_{i}=d_{i 0}\left(1+\varepsilon_{i} \frac{p_{i}-p_{i 0}}{p_{i 0}}\right)
$$

where, $d_{i}$ denotes a domestic final demand of sector $i, d_{i 0}$ denotes a initial quantity of the domestic final demand of sector $i, \varepsilon_{i}$ denotes a price elasticity of domestic for output of the sector $i, p_{i}$ denotes a price of the domestic demand of sector $i$, and $p_{i 0}$ denotes a price of the initial domestic demand for output of sector $i$.

In this paper, the export competition is supposed as Cournot competition, so export is determined as follows:

$$
\begin{aligned}
\max _{w_{i}} & p_{i}^{a}\left(w_{i}\right) w_{i}-c_{i} w_{i} \\
\text { subject to } & p_{i}^{a}\left(w_{i}\right)=a-b\left(w_{i}+w_{i}^{a}\right) \\
& c_{i}=p_{i}\left(A_{i}-M_{i}\right)+k_{i}, w_{i} \geq 0
\end{aligned}
$$

where, $p_{i}{ }^{a}$ denotes an import demand function of sector $i, w_{i}$ denotes an export of sector $i, a$ denotes a constant term of an import demand function, $b$ denotes a coefficient of an import function, and $w_{i}{ }^{a}$ denotes a sum of export of sector $i$ in the rest of the countries.

Kyoto Protocol regulates the reduction target on the sum of emissions between 2008 to 2012, hence, we evaluate the averaged value of these period. The data of the input-output matrix and price elasticity, etc, used in this paper are taken from Akazawa, et al. (2002).

\section{THE EXPECTATION DURING 2008 TO 2012}

Looking at the change of $\mathrm{CO}_{2}$ emissions from 1990, it increased in U.S., Japan and France, almost 17\%, $11 \%$ and $2 \%$ respectively, at 2000 . In Russia, it decreased $37 \%$ at 1996 , because of the collapse of the Soviet Union, and the economic confusion after that. In Germany and U.K., it decreased 15\% and $7 \%$ respectively, at 2000 according to the data of UNFCCC (2003).

According to Energy Information Administration (2003), the change of $\mathrm{CO}_{2}$ emissions from 1990 to 2010 , it will increase $33.1 \%, 24.2 \%$ and $5.9 \%$ in U.S., Japan and France, respectively, and it will decrease $20.4 \%, 14.4 \%$ and $0.6 \%$ in Russia, Germany and U.K., respectively.

The expectation of the $\mathrm{CO}_{2}$ emissions of 2010, which represent the averaged emissions between 2008 to 2012, is shown in Table 2. The values in the second and third columns show the percentage change from 1990. The values of France, U.K. and Germany show the reduction targets in EU bubbles. The values in fourth columns show the Forest Absorption Credits admitted in Marrakesh accords, COP7. The values of fifth columns show the amount of surplus emissions of each country, taking into account of the expectations of $\mathrm{CO}_{2}$ emissions and the forest absorptions.

\section{SCENARIO}

As shown in Table.2, Japan, U.S. and EU countries must take additional policies to achieve the reduction targets of the Kyoto Protocol. We will consider carbon tax and emissions trading as the national policy. To evaluate the influence on the revenue, the price of emissions trading, and the amount of carbon dioxide emissions, etc, we will consider the case Russia and U.S. ratifies the protocol and joins the emissions trading. Hence, we postulate four scenarios as follows:

$<$ Scenario I $>$

Each country reduces its emissions by the carbon tax, without the emissions trading.

$<$ Scenario II $>$

Each country reduces its emissions by the carbon tax and the emissions trading between Japan and EU.

$<$ Scenario III $>$ 
Each country reduces its emissions by the carbon tax and the emissions trading among Japan, EU and Russia.

\section{$<$ Scenario IV $>$}

Each country reduces its emissions by the carbon tax and the emissions trading among Japan, EU, Russia and U.S.

In these Scenarios, the reduction target of U.S. is the $18 \%$ reduction of emissions per unit GDP, during 2002 and 2012, in Scenario I - III, and the value of Kyoto protocol in Scenario IV.

Table 2. The Expectation of the Averaged Emissions Between 2008 to 2012

\begin{tabular}{crrrrr}
\hline & $\begin{array}{c}\text { Reduction } \\
\text { Target }\end{array}$ & $\begin{array}{c}\text { Expectation } \\
\text { of 2010 }\end{array}$ & $\begin{array}{c}\text { Forest } \\
\text { Absorption }\end{array}$ & $\begin{array}{c}\text { Surplus } \\
\text { Emission } \\
\text { Permit }\end{array}$ \\
\hline Japan & $-6.0 \%$ & $+24.2 \%$ & 13.00 & -79.1 \\
U.S & $-7.0 \%$ & $+33.1 \%$ & 28.00 & -519.1 \\
U.K. & $-12.5 \%$ & $-0.6 \%$ & 0.37 & -18.6 \\
France & $-0.0 \%$ & $+5.9 \%$ & 0.88 & -5.4 \\
Germany & $-21.0 \%$ & $-14.4 \%$ & 1.24 & -17.0 \\
Russia & $-0.0 \%$ & $-20.4 \%$ & 33.00 & +164.8 \\
\hline & & & & $\left(10^{6}\right.$ ton carbon $)$
\end{tabular}

\section{THE $\mathrm{CO}_{2}$ REDUCTION BEHAVIOR, AND THE PRICE OF CARBON TAX}

In general, the more energy efficiency is improved, the more marginal reduction cost of emissions is increased. In this paper, we estimate the marginal reduction cost as an exponential function, based on the United States Department of Energy calculation.

As shown in Fig.1, when the carbon tax $t_{1}$ is imposed, the $\mathrm{CO}_{2}$ reduction rate is improved to the level $S_{1}$, in which the marginal reduction cost is equal to the carbon tax, by the private investment in order to minimize the cost. In this case, $\mathrm{CO}_{2}$ reduction rate means the one kind of index of energy efficiency, where the level of the averaged $\mathrm{CO}_{2}$ emissions per unit production of Asian countries, such as 5 countries of ASEAN, Korea, Taiwan and China, is ' 0 ', and the level of no $\mathrm{CO}_{2}$ emissions is ' 1 '. And $t_{0}$ denotes the present marginal $\mathrm{CO}_{2}$ reduction cost, $S_{0}$ the present $\mathrm{CO}_{2}$ reduction rate.

In the case that the revenue of the carbon tax is assigned to the earmarked funds, all of the revenue can be used for the investment of the $\mathrm{CO}_{2}$ reduction behavior or the purchase of the $\mathrm{CO}_{2}$ emissions permit. But, in the case that the revenue of the carbon tax is assigned to the general funds, only a part of the revenue can be used. As shown in Fig.1, in the case that all revenue is assigned to the investment of the $\mathrm{CO}_{2}$ reduction behavior, the $\mathrm{CO}_{2}$ reduction rate is improved to the level, $S_{2}$, where, $S_{2}$ is the level that the area enclosed by $S_{1}, S_{2}$ and marginal cost curve is equal to the area enclosed by $S_{2}$, ' 1 ' and $t_{1}$. In this case, the private expense is the cost of the private investment, $S_{0}$ to $S_{1}$, and the carbon tax, $S_{2}$ to ' 1 '.

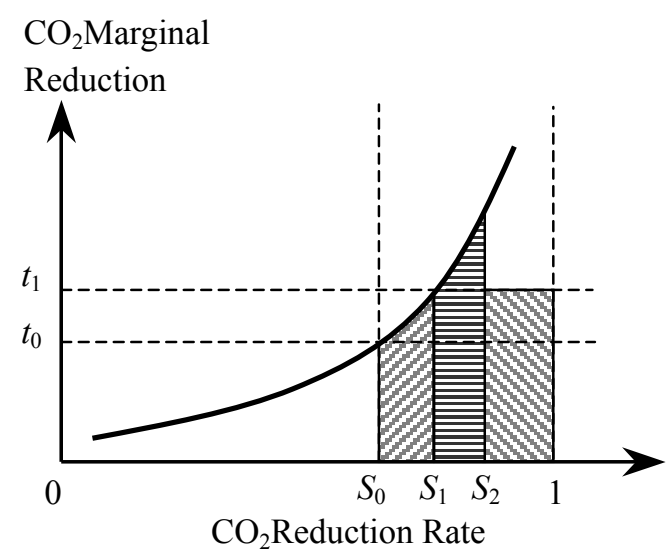

Fig.1. $\mathrm{CO}_{2}$ Reduction Behavior and Carbon Tax

In the international emissions trading, Russia can supply with the emission permit by the monopoly price, which maximizes the income from the emissions trading. Fig.2 shows the relation between the $\mathrm{CO}_{2}$ emissions and carbon tax in the case that the demand of emissions permit is smaller than the maximum supply, such as Scenario II, where, $Q_{0}$ denotes the quantity of $\mathrm{CO}_{2}$ emissions without carbon tax, and $Q_{1}$ the emissions permit. Without the emissions trading, the necessary carbon tax is $t_{1}$. When the price of emissions permit is $t$, the cost of purchase of the emissions permit is equal to the area shown in Fig.2. The income of Russia can be shown as Fig.3, hence, Russia will determine the price of emissions permit as $t_{2}$.

Fig.4 shows the relation between the $\mathrm{CO}_{2}$ emissions and carbon tax in the case that the demand of emissions permit without carbon tax is larger than the maximum supply, such as Scenario III. When the emissions permit price $t$ is lower than the market price, where the demand of emissions permit is 


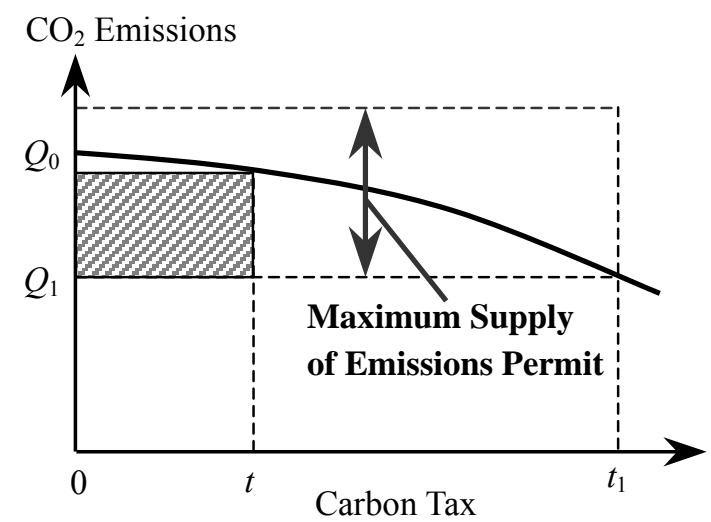

Fig.2. $\mathrm{CO}_{2}$ Emissions Amount and Carbon Tax ( max. demand $<$ max. supply )

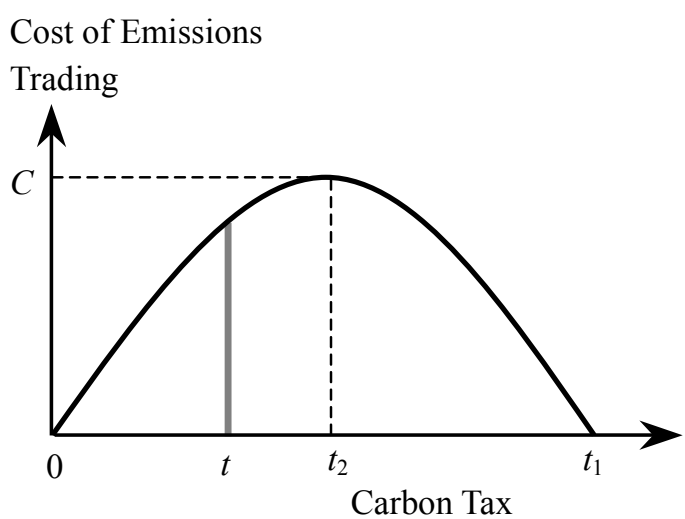

Fig.3. Emissions Trading Cost and Carbon Tax ( max. demand $<$ max. supply )

equal to the supply, the cost to purchase the emissions permit is equal to the area shown is Fig.4. When $t$ is larger than the market price, the cost of emissions trading is similar to the former case. Therefore, the income of Russia can be shown as Fig.5, and we can confirm that the Russia's income is maximized at the market price $t_{2}$.

When the emissions trading cost is covered by the revenue of the carbon tax, the budget limitation is the carbon tax revenue minus the investment to the emission reduction behavior. Hence, in the case that the ratio of investment to the $\mathrm{CO}_{2}$ reduction behavior is zero, the budget limitation is the all of tax revenue. In the case that the investment ratio is 1 , the budget limitation is 0 . Therefore, as shown in Fig.6, we can find the investment ratio, $\alpha$, in which the budget limitation is equal to the cost of emissions trading at the carbon tax, $t_{\alpha}$, which maximize Russia's income.

Fig.1 to Fig.6 show theoretical scenario sketches, but they are confirmed by experimental simulations.

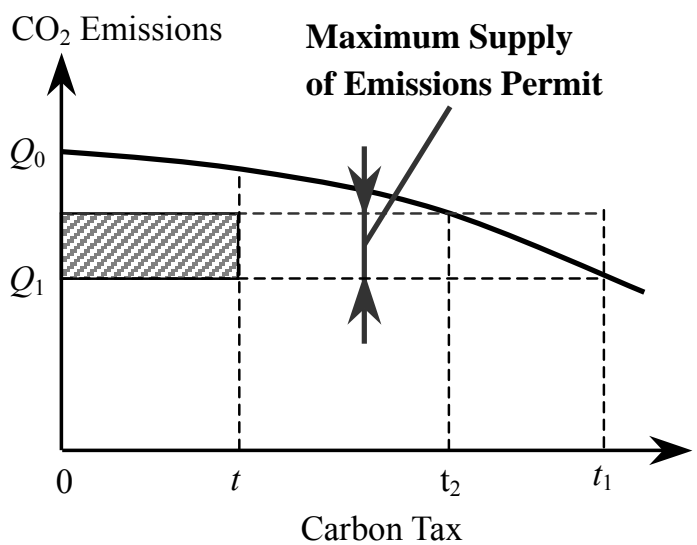

Fig.4. $\mathrm{CO}_{2}$ Emissions and Carbon Tax ( max. demand $>$ max. supply)

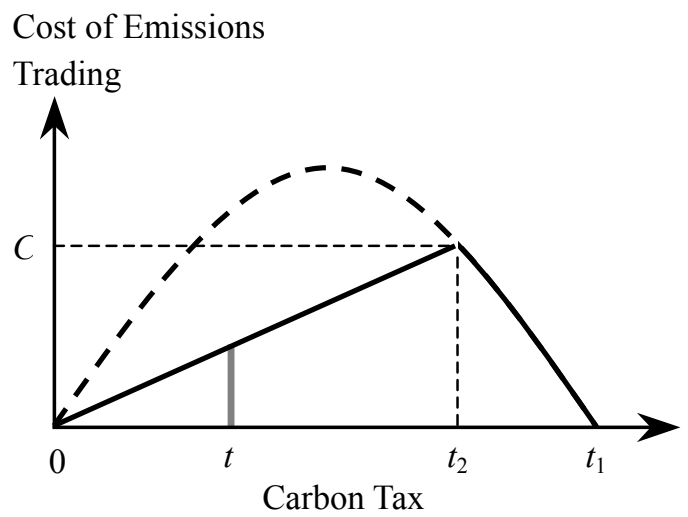

Fig.5. Emissions Trading Cost and Carbon Tax ( max. demand $>$ max. supply )

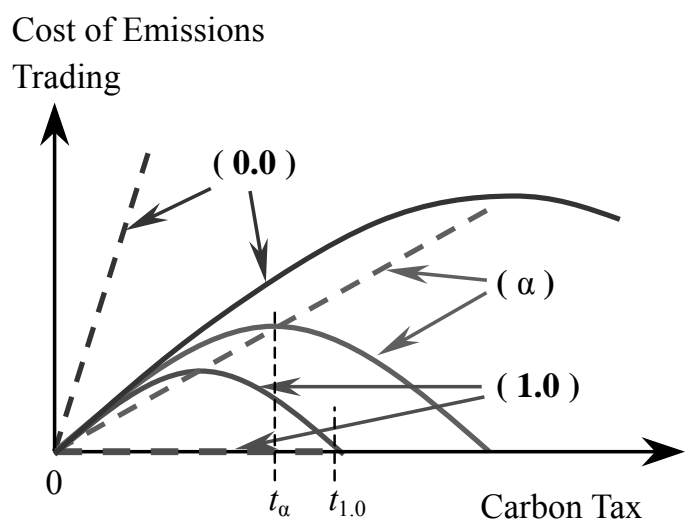

Fig.6. Emissions Trading Cost and Budget Limitation

\section{EVALUATION}

We will compare two cases that the revenue of the carbon tax is assigned to the earmarked funds and to the general funds. For comparison, the ratio of investment to the $\mathrm{CO}_{2}$ reduction behavior is assumed to be zero in the general funds case. 
Table 3 shows the necessary carbon tax to achieve the emissions reduction target of each country for each scenario. We can find that the carbon tax is reduced to one fourth or fifth in the earmarked funds case comparing with the general funds case. We also find that the more the range of emissions trading expands, the more the carbon tax is getting lower.

Table 4 shows the influence of each scenario on the profit of each country. These values are the percentage of the profit change caused by the carbon tax. We find that the bad influence on the profit will be reduced to half by joining the emissions trading. We also find that the bad influence on the profit will be reduced to one fourth in the earmarked funds case compared with the general funds case.

Table 5 shows the income of Russia, which is obtained from emissions trading. These values show the percentage of the income to its GDP. In the earmarked funds case, the difference of emissions permit price between scenario II and III are smaller than that in the general funds case, because the increases of the carbon tax exceed the reduction behavior significantly compared with the general funds case. Hence, the price and amount of the emissions trading are both reduced, the income of Russia is reduced to one fifth, and it is influenced largely whether the U.S. ratifies the protocol or not.

Table 3. The Necessary Carbon Tax

(a) The General Funds Case

\begin{tabular}{crrrc}
\hline Scenario & \multicolumn{1}{c}{ I } & \multicolumn{1}{c}{ II } & \multicolumn{1}{c}{ III } & IV \\
\hline Japan & 230.0 & 197.0 & 130.0 & 114.3 \\
U.S & 82.9 & 82.9 & 82.9 & 114.3 \\
U.K. & 145.2 & 145.2 & 130.0 & 114.3 \\
France & 223.9 & 197.0 & 130.0 & 114.3 \\
Germany & 181.3 & 181.3 & 130.0 & 114.3 \\
\hline
\end{tabular}

(b) The Earmarked Funds Case

\begin{tabular}{crrrr}
\hline Scenario & \multicolumn{1}{c}{ I } & \multicolumn{1}{c}{ II } & \multicolumn{1}{c}{ III } & \multicolumn{1}{c}{ IV } \\
\hline Japan & 57.8 & 31.2 & 15.2 & 24.0 \\
U.S & 4.2 & 4.2 & 4.2 & 24.0 \\
U.K. & 18.2 & 18.2 & 15.2 & 18.2 \\
France & 11.0 & 11.0 & 11.0 & 11.0 \\
Germany & 13.7 & 13.7 & \multicolumn{1}{c}{13.7} & 13.7 \\
\hline & & & \multicolumn{3}{c}{ (\$ ton Carbon ) }
\end{tabular}

Table 4. The Influence on the Profit

(a) The General Funds Case

\begin{tabular}{ccccc}
\hline Scenario & I & II & III & IV \\
\hline Japan & -2.2 & -2.2 & -1.5 & -1.3 \\
U.S & -1.8 & -1.8 & -1.8 & -2.1 \\
U.K. & -1.8 & -1.1 & -1.7 & -1.5 \\
France & -1.2 & -1.1 & -0.7 & -0.6 \\
Germany & -1.9 & -1.7 & -1.5 & -1.2 \\
\hline
\end{tabular}

(b) The Earmarked Funds Case

\begin{tabular}{ccrcc}
\hline Scenario & I & \multicolumn{1}{c}{ II } & III & IV \\
\hline Japan & -0.7 & -0.4 & -0.2 & -0.3 \\
U.S & -0.1 & 0.0 & -0.1 & -0.6 \\
U.K. & -0.2 & -0.3 & -0.2 & -0.3 \\
France & -0.1 & 0.0 & -0.1 & -0.1 \\
Germany & -0.2 & -0.2 & -0.2 & -0.2 \\
\hline & & & & $(\%)$
\end{tabular}

Table 5. The Income of Russia

(a) The General Funds Case

\begin{tabular}{rccc}
\hline Scenario I & Scenario II & Scenario III & Scenario IV \\
\hline 0.00 & 0.00 & 4.02 & 4.33 \\
\hline
\end{tabular}

(b) The Earmarked Funds Case

\begin{tabular}{rccc}
\hline Scenario I & Scenario II & Scenario III & Scenario IV \\
\hline 0.00 & 0.00 & 0.58 & 0.91 \\
\hline & & & $(\%$ of GDP $)$
\end{tabular}

\section{CONCLUDING REMARKS}

Since Japan has already improved the efficiency of energy, it is not rational to achieve the emissions reduction target with the carbon tax only. Joining the emissions trading, the bad influence on the profit will be reduced to half, and it will become more profitable by increasing the number of trading countries. Considering the use of the carbon tax, the bad influence on the profit will be reduced to one fourth in the earmarked funds case compared with the general funds case.

Since Russia is a unique emission permit supplier, it can supply by the monopoly price, and its income will be changed significantly by the other country's policy. In the general funds case, Russia's income will be almost $4 \%$ of its GDP, whether the U.S. will join or not. 
The influence of the carbon tax is concentrated on the particular sectors, such as steel and chemistry product. The case of a reduced carbon tax on such sectors is under evaluation. The details will be presented later.

\section{REFERENCES}

Akazawa, K., N. Sasano, and H. Tamura (2002). Modeling and evaluation of Kyoto Protocol for global environmental protection from economic viewpoint, IFAC $15^{\text {th }}$ Triennial World Congress, Barcelona, Spain.

Energy Information Administration (2003), "International Energy Outlook 2003," Table A10. World Carbon Dioxide Emissions by Region, Reference Case, 1990-2025, http://www.eia.doe.gov/oiaf/ieo/. Energy Journal (1990). Special issue, The cost of the Kyoto Protocol: Multi-model evaluation.

Gaskins, F.W.Jr. and J.P. Weyant (1993). Model Comparisons of the Cost of Reducing $\mathrm{CO} 2$
Emissions, American Economic Review, Papers and Proceedings, 83(2), pp.318-332.

Hertel, T.W., ed. (1993). Global Trade Analysis: Modeling and Applications, Cambridge University Press, Cambridge.

Leontief, W.W. (1970) Environmental Repercussions and the Economic Structure - An Input-Output Approach -, Review of Economics and Statistics, 52, pp.262-271.

Tamura, H., M. Abe, S. Tomiyama and I. Hatano (1998). Evaluating the effectiveness of carbon tax for total emission control of carbon dioxide Systems analysis of a dynamic environmental-economic model, Preprint of $8^{\text {th }}$ IFAC/IFORS/IMACS Symposium on Large Scale Systems: Theory and Applications (LSS'98), pp.589-594, Patras, Greece.

Tamura, H. and T. Ishida (1985). Emissions Control of Regional Environmental Pollution, Ecological Modeling, 30, pp.162-173.

UNFCCC (2003), Greenhouse Gas Inventory Database (GHG), http://ghg.unfccc.int/ . 